\title{
Linguagem e Cultura
}

\author{
Maria Lucia Mexias-Simon \\ Universidade Severino Sombra, Coordenadoria de Recursos Gráficos \\ da FUSVE/USS \\ mmexiassimon@yahoo.com.br
}

\begin{abstract}
Resumo: Tratamos aqui, da língua como manifestação de uma visão do mundo e, ao mesmo tempo, como instrumento formador dessa mesma visão do mundo, num jogo de espelhos, em que a língua suporta e é suportada pela comunidade que a utiliza. Aborda-se, também, a questão de que língua ensinar na escola, frente às diversas variantes.
\end{abstract}

Palavras-chave: Língua Portuguesa. Pragmática. Análise do discurso.

\section{Langage e Culturl}

Resumée: Nous parlons ici de la langue comme vision du monde et, aussi, comme formateur de cette même vision du monde, dans um jeu de miroirs, ou la langue soutient et est soutenue par les gens qui d'elle fait usage. Nous parlons aussi sur la questions: quelle langue on doit presenter à l'école, face sa diversité.

Mots clés: Langue Portugaise. Pragmatique. Analise du discours.

Primeiramente, o que é cultura? Opõe-se a barbarismo? É sinônimo de civilização? É sinônimo de excelência em letras, artes, maneiras? Cultus, entre os romanos, era a devoção aos mortos. Cultura, no infinitivo futuro, forma que, atualmente, não reconhecemos como verbal, significa o que há de ser cultuado, ou cultivado.

No nossos tempos, cultura tornou-se uma palavra indeterminada e variável na sua aplicação a regiões e períodos. A palavra cultura, como muitas outras pode ser tomada em vários significados: refere-se à reverência aos deuses, ao trabalho do campo, opõese a barbarismo. Pode ser tomada como volume de informações detido por pessoa ou grupo de pessoas, como sinônimo de excelência em letras e artes, como erudição (cultura inútil). Tomemos, aqui, cultura no seu sentido antropológico: maneira como as pessoas usam os meios naturais para garantir sua sobrevivência, seu conforto, seu prazer. Não se fará nenhum julgamento de valor a priori, quanto à qualidade, estética ou intelectual de arte, literatura etc. Cultura será, portanto, o conhecimento que a pessoa detém em virtude de ser membro de determinada sociedade. Conhecimento esse que envolve o saber prático, saber se algo deve ser feito de determinada maneira, para melhor resultado, independentemente de sua veracidade real. Não se distingue, nesse momento, o saber teórico do saber prático, ou mesmo da chamada superstição. Em resumo: dá-se o nome de cultura a todas as criações humanas.

Mosaico - Revista Multidisciplinar de Humanidades, Vassouras, v. 3, n. 1, p. 14-24, jan./jun., 2012 
A expressão "língua de cultura" é empregada para distinguir as línguas consideradas culturalmente mais adiantadas. Para Lyons (1982, p.274) cultura deve ser tomada no sentido antropológico, sem nenhum julgamento de valor a priori, quanto à qualidade estética ou intelectual da arte, literatura etc de determinadas sociedades. Nesse ponto de vista, a língua e a cultura de uma nação são manifestações de seu espírito ou de sua mente nacionais distintivos. A linguagem é um traço cultural adquirido em função do indivíduo pertencer a determinada sociedade, mesmo que para isso não haja disposição inata. Por exemplo: uma criança, filha de japoneses, trazida, na primeira infância, para o Brasil, aprenderá a língua portuguesa, se não tiver mais contato com o japonês. Quando desejar aprender o japonês, terá a mesma dificuldade de qualquer criança brasileira. $\mathrm{O}$ idioma é parte da cultura, não há inatismo. O cultural e o emocional na linguagem são interdependentes. Em algumas comunidades, outros tipos de conhecimento terão uma base específica, na espécie, na mesma proporção que a língua tem (religião, conduta etc). Sapir-Whorf desempenharam papel importante na tradição herdada do pensamento europeu que desembocou no estruturalismo. Essa tradição remonta a Herder-Humboldt (in Lyons, 1982), ligada aos princípios do idealismo romântico, que via a diversidade estrutural das línguas (sua forma interna), como produto da faculdade da mente humana, segundo Chomsky. A concepção de Herder-Humboldt da relação entre linguagem e pensamento foi rotulada, pelos estudiosos, de hipótese Sapir-Whorf. Por essa hipótese, a linguagem determina o pensamento, a visão do mundo; por outro lado, não há limites na diversidade estrutural das línguas. Resta o problema do bilinguismo. É sabido que a memória e a percepção são afetadas pela disponibilidade de expressões adequadas. As pessoas tendem a observar e memorizar coisas que são codificáveis na sua língua. Por outro lado, os vocabulários das diversas línguas tendem a ser não-isomórficos (Ex: falta, para o esquimó, uma palavra que traduza neve, no sentido genérico, já que existem várias para as várias situações: neve no chão, neve congelada etc). Mesmo dentro de uma comunidade lingüística a codificação não é constante nem uniforme. Mesmo dentro de uma comunidade lingüística, a codificação não é constante nem uniforme (menina, moça, rapariga, embora significando basicamente ser humano do sexo feminino, não casada, não têm o mesmo peso nas diversas regiões lusófonas, por exemplo). A palavra é sempre um instrumento ideológico. A escolha de uma ou outra forma é determinada por razões ideológicas. Não há discurso inocente. O léxico espelha os valores da sociedade. Mulher honesta, o que vem a ser? Tem o mesmo significado que homem honesto? Por outro lado, apenas no Brasil se pode falar em branco-macumba, verde-bandeira etc.

As línguas mostram os costumes e as características dos povos; Toda teoria é política; O $3^{\circ}$. Mundo traz a questão do desvio técnico e científico a ser resolvida. A globalização trouxe desenvolvimento enorme do volume de informações a serem absorvidas e às técnicas, inclusive das técnicas de escritas. A unidade de Estado se materializa em várias instâncias inclusive a lingüística; a gramática é um objeto histórico, há um nacionalismo; a questão da língua é uma questão de Estado.

Entre duas sociedades, haverá sempre um grau maior ou menor de justaposição lingüística, sendo, obviamente maior o grau de justaposição nas comunidades geograficamente mais próximas. Os recursos produtivos do sistema permitem aos membros do grupo aumentar a própria possibilidade de codificação naquilo que lhes interessa. A hipótese Sapir-Worfh 
esbarra no fato de que, quando as pessoas adquirem segunda língua, conseguem lidar com as categorias dessas línguas. As categorias gramaticais, então, não influenciam os padrões de comportamento A língua é arbitrária em relação ao meio físico, ao contrário da indústria e da agricultura, que dependem dos recursos naturais, e da religião, que é ligada às condições de vida. Isso faz da língua uma instituição mutável. As modificações são teoricamente aceitáveis, dado o caráter arbitrário das formas que estão em vigor. As línguas só não mudam mais velozmente, pelo peso da tradição, que marca certas formas como corretas e outras como erradas. Por outro lado, os elementos lingüísticos formam uma estrutura, onde se apoiam e se reforçam mutuamente. A língua usa sons que são fenômenos físicos (mundo inorgânico), produzidos pelos órgãos da fala (mundo orgânico), que criam comunicações com propósito claro e definido (linguagem - mundo superorgânico). A linguagem é criação do homem, tanto quanto a habitação, os instrumentos etc, ou as criações mentais (religião, direito etc); é, como já se disse, cultural. Por outro lado, a língua é transmissora de cultura, sendo essa a sua finalidade (a oração na religião, as leis no direito etc); transmite, também ordens, instruções etc. A língua, frente à cultura é;

- O seu resultado, ou sua súmula;

. O meio de operação;

- A condição para subsistência.

A língua tem, na cultura, sua razão de ser, não é apenas um recurso para expressar pensamentos, emoções e vontades. É também um meio para chegar a esses estados mentais. Há uma aderência do pensamento às palavras. A(s) língua (s) figura entre as instituições sociais. Falar é sempre um ato social (há distinção entre língua e fala). O indivíduo não cria a linguagem. Faz uso daquela que a sociedade lhe ministrou. É uma pauta sobre a qual se realizam os discursos sociais (V. funções da linguagem, segundo Bühler, e segundo Jakobson in Mattoso, 1964). A linguística, segundo Vossler e seus seguidores, pode ter uma abordagem pela estilística. $\mathrm{O}$ estudo linguístico focaliza a expressão do que se passa na mente humana. Por outro lado, traduz um pensamento socializado. Oferece subsídios, portanto, à psicologia individual, ou à social, mas não deve ser com elas confundido. Por exemplo: registra-se, em português, a existência de gêneros gramaticais masculino e feminino, quando em outras línguas há o gênero neutro. Não se pesquisam, em linguística causas sociológicas ou psicológicas para esse fato.

Como já se disse, a linguagem é um dos traços culturais adquiridos (a par de outros, como religião, conduta etc) em função de o indivíduo pertencer a determinada comunidade, não havendo, para isso, disposição inata, nem limitação física, como acontece com habitação, vestuário etc. por outro lado, o indivíduo não cria a linguagem, faz uso daquela que a sociedade lhe transmitiu. Não há limites nas diversas estruturações lingüísticas, o número de sentenças a serem geradas é infinito. Como exemplo já muito citado, os aborígenes da Austrália só contam até quatro(mesmo tendo cinco dedos na mão como todas as pessoas). Entrando em contato com outros povos, que usem o nosso sistema de contagem, aprendem, sem grande demora, a contar como nós. 
Enquanto só podemos codificar aquilo que nos é conhecido, os próprios recursos do sistema permitem aos falantes aumentar a possibilidade de codificação, quando interessa, ou surge a necessidade, não sendo a língua uma finalidade em si mesma e sim um fator de expressão e comunicação social. É uma pauta sobre a qual se realizam os diversos atos de fala. É, também, acompanhamento de cada fato social, permitindo atuação dos membros da comunidade, uns sobre os outros. Daí o caráter mutante das línguas. Todas as línguas estão em mutação, só não mudam mais pelo peso da tradição (gramática e dicionário). Há sempre lacunas lexicais e não só lexicais. (podemos citar como exemplo o aparecimento dos muitos pronomes de tratamento na Idade Média, quando a vida na corte se complicou em vários graus de nobreza). Porém, em regra, os elementos gramaticais são os mais resistentes às mudanças: preposições, conjunções, flexões verbais, constituindo esses elementos a gramática da língua, o cimento que faz a soma dos demais elementos, os chamados elementos lexicais. Mattoso (1964) não considera esses elementos como palavras, e sim como instrumento gramaticais, pois seu peso semântico é mínimo e não representam elementos do mundo real. Está sempre em aberto, portanto, o inventário dos nomes e verbos, o que podemos observar, facilmente, apenas no terreno da informática. Para Humboldt, ${ }^{1}$ a diversidade entre as línguas não é só uma questão de sons e signos, é uma questão de visão do mundo, de diferentes perspectivas. Quando se passa de uma língua a outra, perde-se a perspectiva. Lacan ${ }^{2}$ diz que nenhuma linguagem pode dizer toda a verdade de outra linguagem, porque ambas são apenas elementos dispersos de uma linguagem inicial e onipresente.

$\mathrm{O}$ fato de que, em qualquer comunidade, existem variações lingüísticas de acordo com as diferentes regiões em que vivem os falantes de uma mesma língua, assim também como essa língua pode variar de acordo com a classe social, a faixa etária, o sexo etc dos falantes, é facilmente verificado por qualquer leigo.

Em virtude da grande variação possível em todos os sistemas lingüísticos, torna-se de grande interesse educacional fazer um levantamento das variedades lingüísticas de uma comunidade, que tipos de pessoas as praticam e qual a visão que elas têm do seu modo de falar e do modo de falar das outras pessoas com quem interagem. Nesse levantamento, deve-se observar os seguintes dados:

- qual a variedade majoritária? (falada por mais de $25 \%$ da população)

- quais as variedades minoritárias? (faladas por $5 \%$ a $25 \%$ da população)

- quais as variedades especiais? (usadas para fins religiosos, literários, grupos etários)

- existem línguas usadas por grupos particulares ou para eventos oficiais?

- no caso de existência de mais de uma língua, qual a que é ensinada nas escolas e qual a praticada na comunicação com outras nações?

A partir dessa observação, pode-se tentar responder questões como as seguintes:

- Qual a variedade de língua que deve ser ensinada nas escolas?

- Como padronizar a modalidade escrita?

- Que padrão estabelecer para a difusão pela mídia?

Mosaico - Revista Multidisciplinar de Humanidades, Vassouras, v. 3, n. 1, p. 14-24, jan./jun., 2012 
Para a determinação de qual variedade linguística de uma comunidade deve ser ensinada nas escolas de modo a favorecer a integração dos indivíduos sem distúrbios decorrentes desajustes sociais, é necessário levar em conta que:

- as modalidades escrita e oral de uma mesma língua tendem a apresentar diferenças inevitáveis;

- a língua se altera no eixo do tempo, causando a desatualização dos modelos ensinados na escola;

. existem diferentes registros lingüísticos;

- a comunidade elabora estereótipos a respeito das variedades linguísticas; algumas são mais prestigiadas que outras.

- entre professores e alunos podem aparecer diferenças de linguagem que beiram a diglossia e o desentendimento; o mesmo se pode dizer em relação aos textos escolares e a variedade dos alunos.

Tem-se como legítimo, o ensino na escola da chamado norma-padrão, que abrange:

. tudo que é de uso comum e corrente numa comunidade lingüística;

- sistema de instruções que definem o que deve ser escolhido entre os usos de uma dada língua para ser conformado a um modelo estético e sócio-cultural. Este conceito é basicamente prescritivo e fundamente a gramática normativa. Essa norma corresponde a usos e atitudes de um determinado segmento da sociedade, justamente o que desfruta d e prestígio social, político e econômico. É nessa definição que se encaixa a norma padrão.

Daí partindo, temos o objeto da Filologia - estudo de uma sociedade através de seus registros escritos (já que registros orais, antigos não os há). Portanto, a primeira tarefa do filólogo é garantir a autenticidade do texto, por processos científicos. Uma vez autenticado o material de trabalho, esbarramos na dificuldade de passar a visão do mundo expressa em um idioma a outro idioma, que recorta outra visão do mundo.

Passemos a abordar alguns exemplos:

Na obra $A$ Republica de Platão (em grego politeia) não se trata de república, tal como a conhecemos - forma de governo. Trata-se da coisa pública, de modo geral: Res publǐca, mesmo porque república, tal como a entendemos, não havia então.

- Pathos, em grego, pode ser emoção, sensação, sentimento, que em português têm significados diversos. A qual desses significados Aristóteles se refere, na sua Poética? Já o verbo poios tinha o significado de criar; A Poética trata da criação (no caso, a literária) não necessariamente em forma de poesia, tal como a entendemos. 
- Tomando o Novo Testamento com documento histórico: é vazado na linguagem oriental, revela o pensamento oriental, com sua visão do mundo. Contar histórias para passar ensinamentos sempre foi costume dos povos semitas. Inicialmente, o Evangelho, pelo menos o de $\mathrm{S}$. Mateus, foi escrito em aramaico, muito tempo depois de decorridos os fatos a que se refere. Os Evangelhos de Marcos, Lucas e Mateus são chamados sinóticos, pois guardam uma certa semelhança. O Evangelho de João é o mais distante dos fatos. Trata-se de um ancião contando suas memórias. Usa expressões como "filhinhos". Lucas, como médico, era o mais instruído: cita como o Menino Jesus foi enfaixado ao nascer. Já na passagem da mulher que padece de um fluxo de sangue, os Evangelistas, exceto Lucas, mencionam ter ela gasto muito dinheiro com médicos. Marcos, o menos instruído, na acepção corriqueira da palavra, faz frases incompletas, com falta do verbo da oração principal, traço típico de quem não tem muita intimidade com a linguagem escrita.

Como era de se esperar, os Evangelhos tiveram poucos leitores, pelo analfabetismo em geral, da época, sobretudo dos primeiros cristãos. Do aramaico, os Evangelhos foram passados ao grego, mas no grego mais simples que o de Platão, a Koiné, já que o Cristianismo penetrou a Europa pelas classes mais humildes. Usou-se, por exemplo, o termo diabo (do grego diabolos - dia $=$ através + bolos $=$ lançar). Diabo é, portanto, aquele que lança obliquamente, "que joga verde para colher maduro", não necessariamente o ser que habita regiões extra-terrenas, nem o que aplica terríveis castigos.

Na passagem em que Jesus pergunta a Pedro, três vezes: - Tu me amas? - em cada vez usa-se um verbo diferente em aramaico e em grego, indicativo de formas diferentes de amar. Na terceira vez, Pedro se entristece. Aparentemente estaria Jesus duvidando de, ou testando o amor de Pedro, já que a versão latina não consigna as diversas formas de amar. Na verdade, Pedro sente uma despedida, quando a pergunta é: - Tu me amas como Deus?

Quando os discípulos perguntam: És Elias, és esse ou aquele outro profeta? Foi dito: $\underline{\text { Ho }}$ propheta eis (És o profeta), isto é o maior dos profetas, o profeta padrão. No Latim, como não há artigos, perdeu-se a expressividade. Uma solução seria ter usado um pronome demonstrativo - aquele profeta és.

- Ainda no Latim, infernus é aquilo que está em posição inferior em relação ao falante, (comparativo de infra) não necessariamente um lugar de punição eterna. Como pelos vulcões e fontes de água quente, sabia-se haver fogo sob a crosta terrestre, associou-se inferno a fogo eterno e daí a castigo.

. Em uma das Epístolas, Paulo diz: “Essas palavras escrevo em grandes letras, com a minha própria mão". Não se trata, como se poderia pensar de palavras mais importantes que outras e sim escritas sem ajuda de um discípulo (geralmente Timóteo ou Barnabé), naquele momento, já que Paulo enxergava com dificuldade. 
- Passando ao nosso idioma: temos o primeiro documento escrito em puro português em Camões, com Lusíadas, celebrando o grande feito dos lusitanos. Enquanto Gil Vicente usava castelhanismos e D. Dinis usava provençalismos, por modismo, ou proximidade geográfica, Camões produziu a primeira obra no português dito castiço, sem misturas. O poema foi escrito em Goa, onde o autor estava em semi-desterro, pelas suas aventuras amorosas. Foi nomeado "curador de defuntos e ausentes" o que lhe dava lazer suficiente para produzir sua obra e, por outro lado, deixava-o a salvo de outras influências, uma vez que havia poucos europeus nas redondezas. Assim ganhamos todos o grande monumento da língua portuguesa.

Em resumo, a língua, através das obras nela vazadas, mostram uma visão do mundo. É manifestação de uma cultura, necessita de uma cultura que lhe dê suporte, sendo a própria língua também suporte dessa cultura. Daí o fracasso das línguas artificiais. O Esperanto é a $35^{\mathrm{a}}$ tentativa, na história da humanidade, de se criar uma língua artificial. Daí, também, o perigo do abuso dos estrangeirismos, quando desnecessários, quando usados apenas para dar aparência de modernidade, ou, ainda mais lamentável, como negação da própria cultura em favor de outra tida como superior. 


\section{Notas}

1 In: Lyons, 1987

2 Idem

\section{Referências}

BACEGA, Maria Aparecida. Concordância verbal. S. Paulo: Ática, 1989.

BASSETO, Bruno. Elementos de filologia românica. São Paulo: EDUSP, 2001.

BRAM, Joseph. Linguagem e sociedade. Rio de Janeiro: Bloch Editores, 1968.

CHOMSKY, Noam. Linguagem e pensamento. Petrópolis: Vozes, 1988.

HALLIDAY, M. A. K. et alii. As ciências lingüisticas e o ensino das línguas._Petrópolis: Vozes, 1974.

ILARI, Rodolfo. A lingüistica e o ensino da língua portuguesa. S. Paulo: Martins Fontes, 1989.

LYONS, John. Linguagem e linguística. Rio de Janeiro: Guanabara Koogan, 1987.

MATTOSO CÂMARA JR, Joaquim. Princípios de linguística geral. Rio de Janeiro: Acadêmica, 1964. 